\title{
COMPARATIVE STUDY OF SHAPING ABILITY OF REVO-S AND ONE SHAPE NICKEL-TITANIUM ROTARY SYSTEMS IN CURVED ROOT CANALS. (AN IN VITRO STUDY)
}

\author{
Mohamed Atef Mohamed*, Magdy M.Ali**, \\ Yaser F. Hussein ${ }^{* * *}$ and Mohamed M. Kattaia****
}

\begin{abstract}
Aim of the study: was to compare the shaping ability of One Shape, Revo-S NiTi rotary instruments, and stainless steel K-Flexofile instruments when used to prepare curved root canals.

Methodology: A total of sixty mesiobuccal root canals of extracted human permanent mandibular molars were used. Those had curvature ranging between $20^{\circ}-40^{\circ}$, radius of curvature between $4-10 \mathrm{~mm}$, and length of curved part between 6-8 $\mathrm{mm}$. The samples were divided into three groups of 20 teeth each according to the instrument used. Using Digora system, the degree of straightening was calculated by comparing pre and post-instrumentation radiographs. Using cone beam computed tomography, mesial and distal dentin thicknesses were measured pre and postinstrumentation, and then applied in an equation given by Gambill et al., to calculate the centering ratio and transportation of the canals. Both rotary systems showed good centering ability and less canal straightening and transportation compared with stainless steel K-Flexofile, with no significant difference between the rotary systems.
\end{abstract}

Results: Tukey's pair-wise test showed that K-Flexofile showed the highest mean degree of straightening, degree and direction of canal transportation and the centering ability while One Shape had the lowest mean. No statistically significant difference was found between One Shape and Revo-S.

Conclusion: Both rotary systems caused less transportation and remained better cantered in the canal than stainless steel K-Flexofile instruments, with no significant difference between One Shape and Revo-S.

* Endodontic Department, Assuit University.

** Ass. Prof of Endodontics, Faculty of Dentistry, Minia University.

*** Ass. Prof of Dental Bio-Material, Faculty of Dentistry, Minia University.

**** Lecturer of Endodontics, Minia University. 


\section{INTRODUCTION}

Stainless steel hand instruments are being used for cleaning and shaping of root canals, but they are not efficient enough in preparation of narrow and curved canals due to the instruments inherent stiffness. Larger sizes of stainless steel files can cause alterations in root canals such as strip perforations, ledges, zips and transportation.

These mishaps urged the development of a new generation of rotary endodontic instruments made of nickel-titanium (Ni-Ti) alloy. The increased flexibility of $\mathrm{Ni}-\mathrm{Ti}$ instruments aids in safe preparation of curved canals.

These instruments differed in geometric construction, operating speed and torque. Researches were carried out to evaluate shaping abilities and mechanical properties of these newly introduced rotary Ni-Ti to get maximum benefit of their clinical performance.

Revo-S (Micro-Mega) instruments (SC1 and $\mathrm{SU})$ have an asymmetric cross-section design with an inactive tip. Only the SC2 instrument has a symmetric cross-section design.

Recently, a new concept in root canal preparation has been introduced with the New One Shape (Micro Mega, Besancon Cedex, France), which is claimed to complete canal shaping with only a single file in continuous rotation. The One Shape file is a single system that presents a variable asymmetrical crosssectional geometry along the blade.

\section{MATERIALS AND METHODS}

- Specimens selection, preparation and grouping

Only 60 teeth with mesiobuccal root canals satisfying the following canal parameters were included in the study:

- The mesiodistal canal curvature range between 20 and 40 degrees.

- The radius of curvature of the canal range from 4 to $10 \mathrm{~mm}$.
- The length of the curved part of the canal between $6-8 \mathrm{~mm}$.

The following measurements were recorded for each canal before instrumentation:

A) Parameters of canal curvature using direct digital radiography:

- The angle of the curvature.

- The radius of the canal curvature.

- The length of the curved part.

B) Root dentin thickness using cone beam computed tomography.

The blocks were randomly divided into three equal groups of twenty teeth each, according to the type of instrument used:

Group A: 20 canals were instrumented using One Shape system.

Group B: 20 canals were instrumented using Revo-S system.

Group C :20 canals were instrumented using hand flexible stainless steel files ( $\mathrm{K}$ - Flexofiles ).

\section{A) Pre-instrumentation canal curvature measurements:}

Using direct digital radiography, each tooth was radiographed from the buccal view with \#15 $\mathrm{k}$-file inside the mesiobuccal canal adjusted to the apical foramen. A Minary x-ray machine (Soredex, Finland) with exposure parameters $60 \mathrm{Kv}, 10 \mathrm{~mA}$, and 0.03 second exposure time was used. Digital images were captured by Digora large plate sensor

- The angle of curvature: According to the Schnider' ${ }^{[1]}$ method, pre-instrumentaion canal curvature was measured. A \# 15 file was used as indicator of canal direction and orientation throughout the length of the root. A straight line was drawn along the file in the coronal straight portion of the canal. A second line was drawn from apical foramen to intersect the first line 
at the point where the canal began to leave the long axis. The intersection of these two lines forms an interior angle which was considered as the angle of the curvature.

- The radius of curvature: it was measured according to the method described by Schäfer et al $2002^{[2]}$. The radius of the curvature was calculated on the basis of the geometrical principles of an isosceles triangle. From the previous step, the angle of curvature and the length of the second line (from the apical foramen to point where the canal began to leave the long axis) were measured and applied in the following equation:

$$
r=s / 2 \cos \alpha
$$

- The length of the curved part: it was calculated on the basis of the following formula:

$$
k=4 \pi r \alpha / 360,
$$

Where for both formulae:

$r$ : The radius of curvature

$\alpha$ : The angle of curvature measured according to schnider.

$\mathrm{s}$ : The of the chord of the hypothetical circle (AB line).

$\mathrm{k}$ : The length of the curved part.

\section{B) Pre-instrumentation root canal dentin thickness}

The 20 blocks of each group were arranged in special fabricated box $(10 \mathrm{x} 8 \mathrm{~cm})$ with the buccal surface of all samples facing the same direction. The teeth were scanned using Cone Beam 3D X-ray system (Scanora 3D, soredex, Finland). The images were captured in a large field of view $(7.5 \mathrm{~cm})$ with a resolution of 0.25 voxels (maximum resolution) and exposure time of 3 seconds.

Using OnDemand3D software, axial cuts were carried out at $3 \mathrm{~mm}, 5 \mathrm{~mm}$, and $8 \mathrm{~mm}$ from the apex. The canal space was demarcated for better contrast. At each level, the shortest distances for mesial and distal dentin thickness were measured and defined as the distance from the outside the root to the periphery of the canal.

Instrumentation was carried out with an attempt to standardize the shape of instrumented canals and make them comparable.

Each group was prepared with the assigned instrumentation system, using $5 \mathrm{ml}$ of normal saline after each instrument. While lubrication of the instruments was always ensured using K-Y Gel.

For both groups (A) and (B), EndoPocket (ATR, Italy) endodontic electric motor was used with speed $350 \mathrm{rpm}$ as recommended for both systems, torque $2 \mathrm{Ncm}$, with gear reduction 16: 1 contrangle .

The same steps of pre-instrumentation radiograph were followed:

a) Post-instrumentation canal curvature using direct digital radiography. The master apical file was used for easy tracing the prepared canal during measurement.

b) Post-instrumentation root canal dentin thickness at the same levels using cone beam computed tomography CBCT.

The shaping ability of the instruments used was assessed by calculating:

\section{1) Changes in canal curvature(degree of straightening):}

Differences in the angle of curvature were calculated by comparing the final values and the initial values. The difference between the two values was considered as the degree of straightening.

\section{2) Degree and direction of transportation:}

\section{a) Degree of transportation}

The following equation (Gambill et al,1996) ${ }^{[3]}$ was used to measure transportation at the predetermined levels:

$$
\text { (X1-X2)-(Y1-Y2) }
$$




\section{b) Direction of transportation}

From the previous equation, negative value indicated transportation toward distal direction (inner side of the curvature) while positive value indicated transportation toward mesial portion (outer side of the curvature).

\section{3- Centering ratio: using cone beam computed to- mography CBCT.}

Gambill et al. 1996, the mean centering ratio indicates the ability of the instrument to stay centered in the canal, also defined the following equation to measure the centering ratio:

* Centering ratio: X1-X2/Y1-Y2

According to this formula, a result of (1) indicates perfect centering.

Where for both formulae:

$\mathrm{X} 1$ : represent pre-instrument mesial side dentin thickness.

X2: represent pos-tinstrument mesial side dentin thickness.

Y1: represent pre-instrument distal side dentin thickness.

Y2: represent pos-tinstrument distal side dentin thickness.

\section{RESULTS}

\section{1-Degree of straightening}

The mean and standard deviation of degree of straightening were $0.48 \pm 0.38,0.68 \pm 0.48$, and $5.02 \pm 1.75$ degrees for One Shape, Revo-S, and KFlexofile groups respectively. ANOVA test showed statistically significant difference among the groups $(P<0.001)$. Tukey's pair-wise test showed that K-Flexofile showed the highest mean degree of straightening while One Shape had the lowest mean. No statistically significant difference was found between One Shape and Revo-S. Figure (1) .

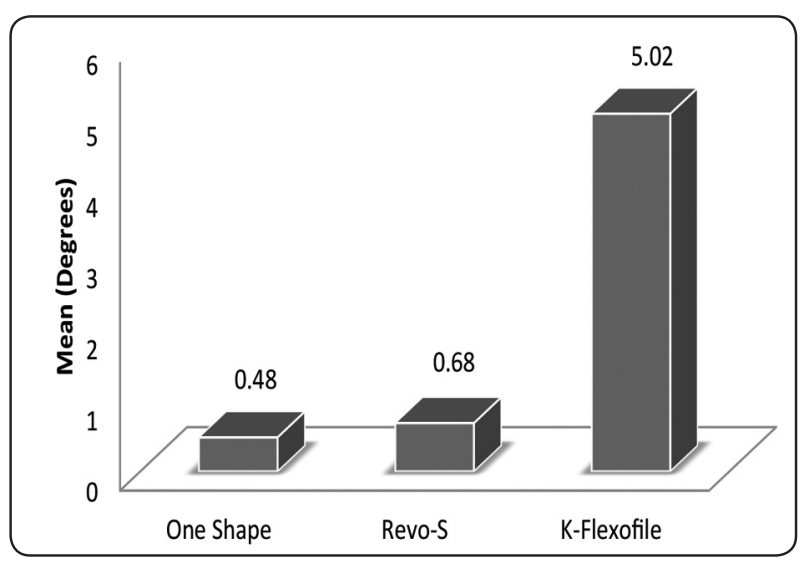

Fig. (1) Histogram showing mean degree of straightening in the three groups.

\section{2- Degree and direction of canal transportation}

According to the equation given by Gambill et al., dentin thicknesses was used to measure the canal transportation, which represents the amount and direction of canal deviation from its original path, a value of 0 indicates no canal transportation. A negative value indicates transportation toward the distal direction, while positive value indicates transportation toward mesial direction.

\section{A) Degree of transportation}

Comparison between the three groups: (Figure 2)

\section{a) At the apical level (3 $\mathrm{mm})$ :}

The mean and standard deviation values were $0.025 \pm 0.019, \mathrm{~mm}, 0.025 \pm 0.018 \mathrm{~mm}$, and $0.132 \pm$ $0.071 \mathrm{~mm}$ for One Shape, Revo-S, and K-Flexofile groups respectively. Kruskal-Wallis test showed statistically significant difference among the groups $(P<0.001)$. Mann-Whitney $\mathrm{U}$ test showed that K-Flexofile showed the statistically significantly highest mean transportation. There was no statistically significant difference between One Shape and Revo-S. 


\section{b) At the middle level (5 $\mathrm{mm})$ :}

The mean and standard deviation values were $0.025 \pm 0.019 \mathrm{~mm}, 0.035 \pm 0.028 \mathrm{~mm}$, and $0.110 \pm$ $0.045 \mathrm{~mm}$ for One Shape, Revo-S, and K-Flexofile. Kruskal-Wallis test showed statistically significant difference among the groups $(P<0.001)$. MannWhitney $U$ test showed that K-Flexofile showed the statistically significantly highest mean transportation. There was no statistically significant difference between One Shape and Revo-S.

\section{c) At the coronal level:}

The mean and standard deviation values were $0.026 \pm 0.022 \mathrm{~mm}, 0.030 \pm 0.021 \mathrm{~mm}$, and $0.178 \pm$ $0.078 \mathrm{~mm}$ for One Shape, Revo-S, and K-Flexofile respectively. Kruskal-Wallis test showed statistically significant difference among the groups $(P<0.001)$. Mann-Whitney $U$ test showed that K-Flexofile showed the statistically significantly highest mean transportation. There was no statistically significant difference between One Shape and Revo-S.

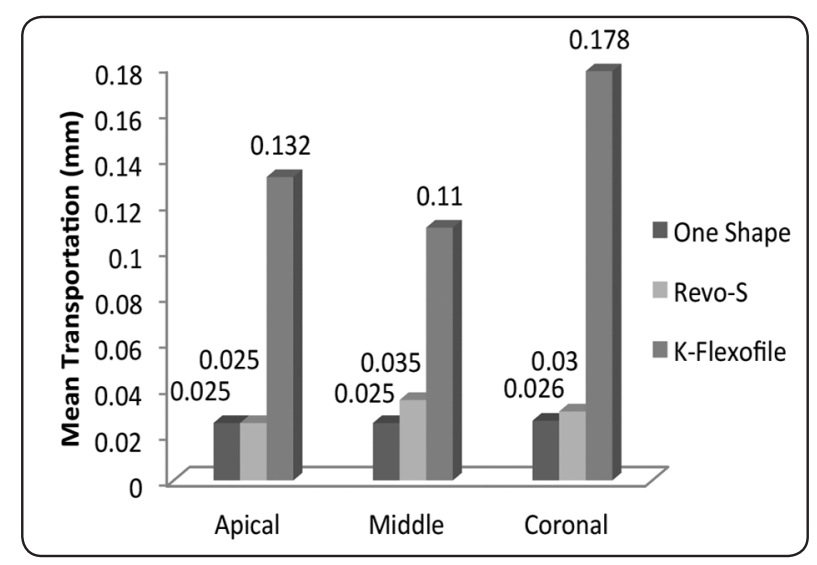

Fig. (2) The mean transportation in the three groups at different levels.

\section{B) Direction of transportation}

Direction of transportation data were presented as frequencies and percentages. Chi-square $\left(\mathrm{x}^{2}\right)$ test was used to compare the direction of transportation in the three groups (Figure 3).

\section{Comparison between the three groups:}

\section{a) At the apical level:}

With One shape: 12 canals (60\%) showed mesial transportation while 8 canals (40\%) showed distal transportation. With Revo-S: 14 canals (70\%) showed mesial transportation while 6 canals (30\%) showed distal transportation. With K-Flexofile: 20 canals (100\%) showed mesial transportation.

Chi-square test showed statistically significant difference among the groups $(P<0.05)$. K-Flexofile showed higher tendency of mesial transportation than One shape and Revo-S.

\section{b) At the middle level:}

With One shape: 12 canals (60\%) showed mesial transportation while 8 canals (40\%) showed distal transportation. With Revo-S: 14 canals (70\%) showed mesial transportation while 6 canals (30\%) showed distal transportation. With K-FLexofile: 6 canals $(30 \%)$ showed mesial transportation while 14 canals $(70 \%)$ showed distal transportation.

Chi-square test showed statistically significant difference among the groups $(P<0.05)$. Revo-S and One shape showed higher tendency of mesial transportation than K-Flexofile.

\section{c) At the coronal level:}

With One shape: 17 canals (85\%) showed mesial transportation while 3 canals $(15 \%)$ showed distal transportation. With Revo-S: 14 canals (70\%) showed mesial transportation while 6 canals $(30 \%)$ showed distal transportation. With K-Flexofile: 4 canals (20\%) showed mesial transportation while 16 canals $(80 \%)$ showed distal transportation.

Chi-square test showed statistically significant difference among the groups $(P<0.001)$. One shape and Revo-S showed higher tendency of mesial transportation than K-Flexofile. 


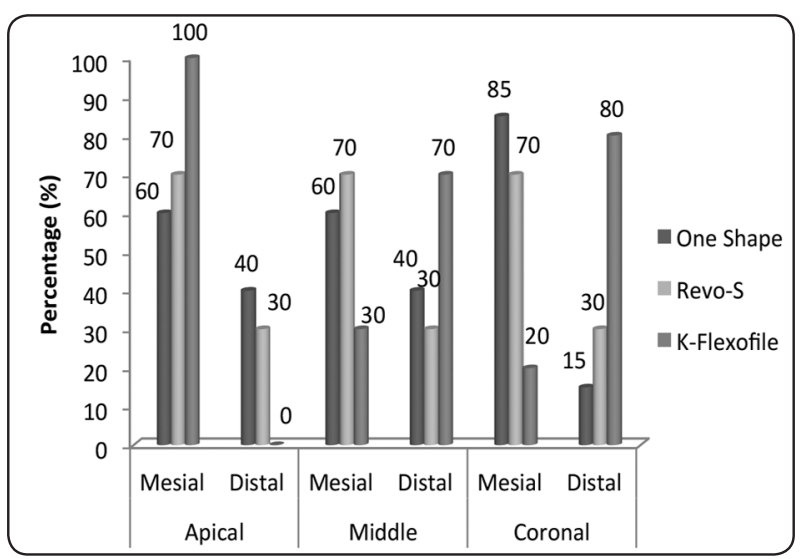

Fig. (3) The frequencies and percentages of transportation direction in the three groups.

\section{3- The centering ratio}

According to the equation used for measuring the centering ratio, which represents the ability of the instrument to remain centered in the canal, a value of 1 indicated perfect centering ability.

\section{Comparison between the three groups: (Figure 4)}

\section{a) At the apical level (3mm from the apex):}

The mean and standard deviation values were 0.83 $\pm 0.10,0.83 \pm 0.09$, and $0.53 \pm 0.09$ for One shape, Revo-S, and K-Flexofile respectively. ANOVA test showed statistically significant difference among the groups $(P<0.001)$. Tukey's pair-wise test showed that there was no statistically significant difference between One shape and Revo-S.

\section{b) At the middle level (5mm from the apex):}

The mean and standard deviation values were $0.83 \pm 0.10,0.82 \pm 0.08$, and $0.56 \pm 0.13$ for One shape, Revo-S, and K-Flexofile respectively. ANOVA test showed statistically significant difference among the groups $(P<0.001)$. Tukey's pair-wise test showed that there was no statistically significant difference between One shape and Revo-S.

\section{c) At the coronal level (8mm from the apex):}

The mean and standard deviation values were $0.89 \pm 0.10,0.88 \pm 0.08$, and $0.51 \pm 0.07$ for One shape, Revo-S, and K-Flexofile respectively. ANOVA test showed statistically significant difference among the groups $(P<0.001)$. Tukey's pair-wise test showed that there was no statistically significant difference between One shape and Revo-S.

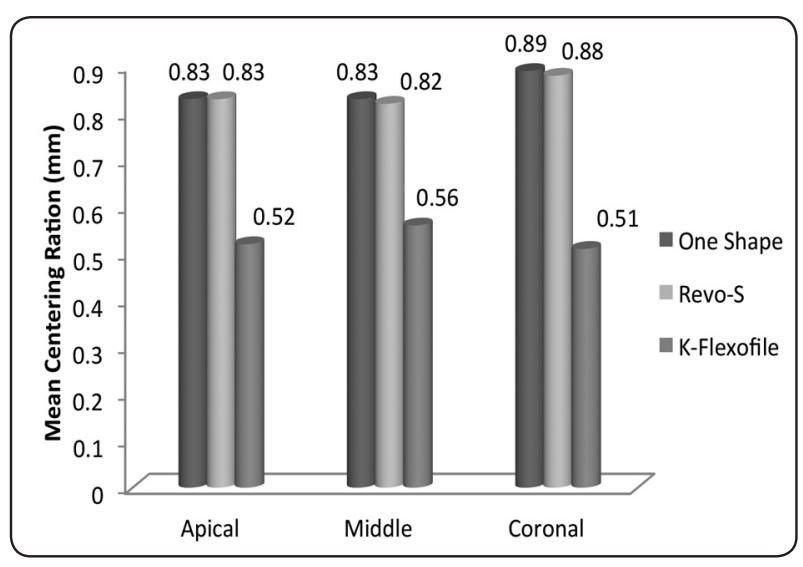

Fig. (4) A histogram showing the mean centering ratio in the three groups at different levels.

\section{DISCUSSION}

Studies showed that canals can have the same angle of curvature while having different radii of curvature ${ }^{[4,5,6]}$. Related to this point Schafer et al.(2002) ${ }^{[7]}$ stated that, to improve the comparability of different studies on instrumentation of curved root canals, curvature should be described by using the angle of the curve according to Schneider's method, with the radius and the length of the curve.

For that reason and to standardize the canal curvature parameters, root canals with angle of curvatures range between 20 and 40 degrees and radius of curvature between $4-10 \mathrm{~mm}$ were used in this study. According to Schneiderf s classification of angle of curvature ${ }^{[1]}$ and Lopes $\mathbf{L}^{\mathbf{f}} \mathbf{s}$ classification of radius of canal curvature ${ }^{[5]}$, the selected range of angle and radius represented severe canal curvature, and it was considered proper condition to evaluate shaping ability and centering performance of the instruments because these characteristics enhance deviation to occur ${ }^{[8,9]}$. 
The length of the curved part of the canal was considered a factor affecting the performance of the instrument inside the canal, as the stress acting on a canal instrument is highest in the curvature zone $^{[1,10]}$, for that, the selected range of the length of the curvature was between $6-8 \mathrm{~mm}$.

The angle of curvature was measured according to Schneider's method because it is considered simple and most common method used for measuring the angle of curvature.

The radius of curvature was measured according to the method described by Schafer et al. (2002) [2]. In this method the radius was calculated mathematically using the pre-measured angle of curvature and the length of straight line chord applied in an equation. This method was preferred to the method described by Pruett et al. (1997) ${ }^{[11]}$, because human error is more probable, as measuring the radius of the curvature geometrically needs multiple tracing measurements (four lines and three points) on the root canal, which may cause variation in the readings.

Schafer' ${ }^{[2]}$ formula was used to calculate the length of the curved part of the root canal. The formula was $\mathrm{k}=4 \pi \alpha \mathrm{r} / 360$.

In the present study, the final apical preparation diameter in the One Shape and Revo-S groups was size 25/.06. This sequence was followed because previous studies considered 25/.06 apical preparation was safe and produced well shaped canals ${ }^{[12,13]}$.

To make the prepared canals through the three groups comparable, it was decided to manage the intervals in the step-back phase of the K-Flexofile group in such a manner to achieve the same taper as other rotary systems used ${ }^{[14,15]}$.

The method used in this study to assess the degree of straightening consisted of subtracting the pre- and postoperative angle of curvature of root canal on radiographs. When the difference between both angles increased, this meant that the used instrument had a tendency to straighten the canal $^{[16,17]}$.

Regarding the degree of straightening of canal curvature, results showed that both NiTi rotary systems, One Shape and Revo-S maintained the original curvature of root canal better than stainless steel instruments, coinciding with other studies ${ }^{[18,19]}$ in which the degree of straightening was less than $1^{\circ}$.

No statistical significant difference was found between both rotary groups, however One Shape showed the least degree of straightening.

Regarding transportation records, which represent the magnitude and the direction of the canal deviation, it was found that both One Shape and Revo-S had less transportation values than K-Flexofile at all levels. That was agreed by others studies showing less distance of transportation in NiTi instruments compared to stainless steel instruments ${ }^{[20,15,21]}$.

Changes in canal curvature after the use of the different NiTi file systems were not statistically significant. This is in agreement with the findings of previous studies ${ }^{[18,22]}$.

Regarding direction of transportation, results showed that, the transportation at the apical level was mainly mesialy in the three groups. That is due to the restoring force within the curved file that exerts stresses and cut more on the outer curvature of the canal. However, incidence of distal transportation at apical level indicated other factors than canal curvature, such as instrument design, physical properties of the alloy, and techniques of preparation ${ }^{[23]}$. At middle and coronal levels, K-Flexofile showed higher tendency for distal transportation (dangerous zone) than One Shape and Revo-S systems, that may be attributed to the stiffness of larger stainless steel files and GatesGlidden burs used at these levels. 
In centering ratio records, which represent the ability of instruments to remain centered in the prepared canals, a value equal to 1 indicated perfect centralization. When this value was closer to zero, it was considered that the instrument had a lower capacity to maintain itself in the central axis of the canal. Results showed that, the ratio at all three levels was significantly better in One Shape and Revo-S groups than in stainless-steel K-Flexofile group $^{[18,22]}$.

\section{CONCLUSIONS}

In review of the results and under the limitations of this study the following was concluded:

Both rotary systems caused less transportation and remained better cantered in the canal than stainless steel K-Flexofile instruments, with no significant difference between One Shape and Revo-S.

\section{REFERENCES}

1- Schneider SW.A comparison of canal preparations in straight and curved root canals. Oral Surg Oral Med Oral Pathol 1971; 2: 271-5.

2- Schafer E, Diez C, Hoppe W, Tepel J. Roentgenographic investigation of frequency and degree of canal curvatures in human permanent teeth. J Endod 2002; 28: 211-6.

3- Gambill JM, Alder M, del Rio CE. Comparison of nickeltitanium and stainless steel hand-file instrumentation using computed tomography. J Endod 1996; 22: 369-75.

4- Estrela C, Bueno MR, Sousa-Neto MD, Pecora JD. Method for determination of root curvature radius using cone-beam computed tomography images. Braz Dent J 2008;19: 114-8.

5- Lopes HP, Elias CN, Estrela C, Siqueira JF Jr. Assessment of the apical transportation of root canals using the method of the curvature radius. Braz Dent J 1998; 9: 39-45.

6- Shen Y, Haapasalo M. Three- dimensional analysis of cutting behavior of nickel-titanium rotary instruments by microcomputed tomography. J Endod 2008; 34: 606-10.

7- Schafer E, Diez C, Hoppe W, Tepel J. Roentgenographic investigation of frequency and degree of canal curvatures in human permanent teeth. J Endod 2002; 28: 211-6.

8- Peters OA, Peters CI, Schonenberger K, Barbakow F. ProTaper rotary root canal preparation: effects of canal anatomy on final shape analysed by micro CT. IntEndod J 2003; 36: 86-92.

9- El Moghazy MA, ElByomi, ElHilaly GM. Comparative study of the efficacy of two newly introduced rotary nickel titanium instruments in shaping of curved root canals. C D J 2008; 24: 447 -56.

10- Bryant ST, Dummer PMH, Pitoni C, Bourba M, Moghal S. Shaping ability of .04 and .06 taper ProFile rotary nickeltitanium instruments in simulated root canals. Int Endod J 1999; 32: 155-64.

11- Pruett JP, Clement DJ, Carnes DL Jr. Cyclic fatigue testing of nickel-titanium endodontic instruments. J Endod 1997; 23: 77-85.

12- Bryant ST, Dummer PMH, Pitoni C, Bourba M, MoghalS. Shaping ability of .04 and .06 taper ProFile rotary nickeltitanium instruments in simulated root canals.IntEndod $\mathrm{J}$ 1999; 32: 155-64.

13- Khalilak Z, Alavi K, Akhlaghi NM, Mehrvarzfar P, Dadresanfar B. Canal-centering ability of three rotary file systems in simulated curved canals: a comparative study. Indian J Dent Res 2009; 20: 400-3.

14- El Moghazy MA, ElByomi, ElHilaly GM. Comparative study of the efficacy of two newly introduced rotary nickel titanium instruments in shaping of curved root canals. C D J 2008; 24: 447 -56.

15- Iqbal MK, Firic S, Tulcan J, Karabucak B, Kim S. Comparison of apical transportation between ProFile and ProTaperNiTi rotary instruments. IntEndod J 2004; 37 : 359-64.

16- Vahid A, Roohi N, Zayeri F.A comparative study of four rotary NiTi instruments in preserving canal curvature, preparation time and change of working length. Aust Endod J 2009; 35: 93-7.

17- Royal JR, Donnelly JC. A comparison of maintenance of canal curvature using balanced-force instrumentation with three different file types. J Endod 1995; 21: 300-4.

18- Çelik D, Taşdemir T, Kürşat Er. A comparison of 6 rotary Nickel-Titanium systems and hand instrumentation for root canal preparation in severely curved root canals of extracted teeth. J Endod 2013; 39( 2) , 278-82. 
19- Bürklein S, Börjes L, Schäfer E. Comparison of the shaping ability of three different nickel-titanium rotary instruments during the preparation of curved root canals in extracted teeth. IntEndod J 2014 ; 47: 470-6

20- Schafer E, Florek H. Efficiency of rotary nickel-titanium K3 instruments compared with stainless steel hand K-Flexofile. Part 1.Shaping ability in simulated curved canals.Int Endod J 2003; 36: 199-207.

21- Kaptan F, Sert S, Kayahan B, Haznedaroglu F, Tanalp $\mathrm{J}$, Bayirli. Comparative evaluation of the preparation efficacies of HERO Shaper and Nitiflex root canal instruments in curved root canals. Oral Surg Oral Med Oral Pathol Oral RadiolEndod 2005; 100: 636-42.

22- Bürklein S, Benten S, Schäfer E.A comparison of the shaping ability of different single-file systems in severely curved root canals of extracted teeth. IntEndod $\mathrm{J}$. Jun2013;46:590-7.

23- Kosa DA, Marshall G, Baumgartner JC. An analysis of canal centering using mechanical instrumentation techniques. J Endod1999;25:441-5. 